Article

\title{
Evolution of the Aroma Volatiles of Pear Fruits Supplemented with Fatty Acid Metabolic Precursors
}

\author{
Gaihua Qin ${ }^{1,2,3, \dagger}$, Shutian Tao ${ }^{1, \dagger}$, Huping Zhang ${ }^{1}$, Wenjiang Huang ${ }^{1}$, Juyou Wu ${ }^{1}$, Yiliu Xu ${ }^{3, *}$ \\ and Shaoling Zhang $1, *$
}

1 Department of Horticulture, Nanjing Agricultural University, Nanjing 210095, China;

E-Mails: qghahstu@163.com (G.Q.); taost@njau.edu.cn (S.T.); zhanghuping@126.com (H.Z.); wenjiangh@126.com (W.H.); juyouwu@njau.edu.cn (J.W.)

2 Horticultural Research Institute, Anhui Academy of Agricultural Sciences, Hefei 230031, China

3 Key Laboratory of Genetic Improvement and Ecophysiology of Horticultural Crop, Hefei 230031, China

$\dagger$ These authors contributed equally to this work.

* Authors to whom correspondence should be addressed; E-Mails: yiliuxu@163.com (Y.X.); slzhang@njau.edu.cn (S.Z.); Tel.: +86-551-62160121 (Y.X.); +86-25-843965801 (S.Z.); Fax: +86-551-65160937 (Y.X.); +86-25-84396485 (S.Z.).

External Editor: Riccardo Flamini

Received: 19 September 2014; in revised form: 13 November 2014 / Accepted: 26 November 2014 / Published: 2 December 2014

Abstract: To examine the biochemical metabolism of aroma volatiles derived from fatty acids, pear fruits were incubated in vitro with metabolic precursors of these compounds. Aroma volatiles, especially esters, were significantly increased, both qualitatively and quantitatively, in pear fruits fed on fatty acid metabolic precursors. Cultivars having different flavor characteristics had distinctly different aroma volatile metabolisms. More esters were formed in fruity-flavored "Nanguoli" fruits than in green-flavored "Dangshansuli" fruits fed on the same quantities of linoleic acid and linolenic acid. Hexanal and hexanol were more efficient metabolic intermediates for volatile synthesis than linoleic acid and linolenic acid. Hexyl esters were the predominant esters produced by pear fruits fed on hexanol, and their contents in "Dangshansuli" fruits were higher than in "Nanguoli" fruits. Hexyl esters and hexanoate esters were the primary esters produced in pear fruits fed on hexanal, however the content of hexyl ester in "Dangshansuli" was approximately three times that in "Nanguoli". The higher contents of hexyl esters in "Dangshansuli" may have resulted from a higher level 
of hexanol derived from hexanal. In conclusion, the synthesis of aroma volatiles was largely dependent on the metabolic precursors presented.

Keywords: pear; aroma volatiles; fatty acid metabolism

\section{Introduction}

Fruit aromas consist of many aroma volatiles, and their formation involves several biosynthetic pathways. Fatty acid metabolism is an important metabolic pathway involved in the biosynthesis of aroma volatiles in fruits. Fatty acids liberated by lipase activity and those further metabolized by $\beta$-oxidative enzymes and/or lipoxygenase (LOX) are generally regarded as the initial precursors of straight-chain esters, alcohols, and aldehydes produced in fruits during development and maturation [1-3].

Transgenic modification of fatty acid metabolism in plant tissues resulted in significant changes in aroma compound profiles [4]. For fruits, higher enzymatic activities and smaller amounts of linoleic acid and linolenic acid were measured in ripe fruits compared to green fruits. Fatty acid deficiency in fruits was the primary cause of the poor aroma of fruits [1,5-8].

Studies examining aroma production in fruits feeding on short or long-chain fatty acids (FA) (up to $16 \mathrm{C}$ atoms) $[2,6,7]$ have shown that aroma production increases, even under conditions in which natural aroma volatiles production is limited by storage. Such results have demonstrated the importance of fatty acids as precursors for aroma volatile biosynthesis and the feasibility of in vitro aroma volatile biosynthesis modifications.

Pyrus bretschneideri Dangshansuli is a pear cultivar widely planted in China for its great size, rich juice and sweet, crisp flesh. The ripe fruits contain many straight-chain aldehydes and alcohols, giving them a "green" flavor note. Pyrus ussuriensis Nanguoli is another cultivar widely planted in the northern China for its attractive color, exquisite flesh and pleasant flavor. Esters are the important volatiles of the ripe fruits, endowing them a "fruity" flavor note [9]. The two cultivars grow well in the Liaoning Province of China and have similar bloom and maturity dates, but their aroma volatile composition and concentration are distinctly different. The majority of plant aroma volatiles originate on a quantitative and qualitative basis from saturated and unsaturated fatty acids [10]. Most aroma volatiles of fruit are biosynthetically derived from fatty acids, however the fatty acid metabolism of aroma volatiles in different cultivars have not been thoroughly examined. In this study, the aroma volatile metabolisms of "Dangshansuli" and "Nanguoli" were examined by incubating fruits with linoleic acid, linolenic acid, hexanol and hexanal to further understand aroma volatile biosynthesis and regulation.

\section{Results and Discussion}

\subsection{Contents of Linoleic Acid and Linolenic Acid for Pear Fruits Feeding on Linoleic Acid and}

\section{Linolenic Acid}

In vitro cultures are useful for examining the biosynthetic pathways of aroma volatiles in fruits [11-13]. The incubation of pear fruits with linoleic acid and linolenic acid showed that these 
compounds were efficiently absorbed by pear fruits (Figures 1 and 2) and used for the synthesis of aroma volatiles. However, different absorbabilities were observed for the two pear cultivars.

Figure 1. Linoleic acid contents of pear fruits feeding on linoleic acid. (A) P. bretschnrideri "Dangshansuli"; (B) P. ussuriensis "Nanguoli"; Values represented means of three replicates, bars were standard deviation from three replicates; * denoted significant difference between treatments and CK, $p<0.05$; ** denoted significant difference between treatments and CK, $p<0.01$.
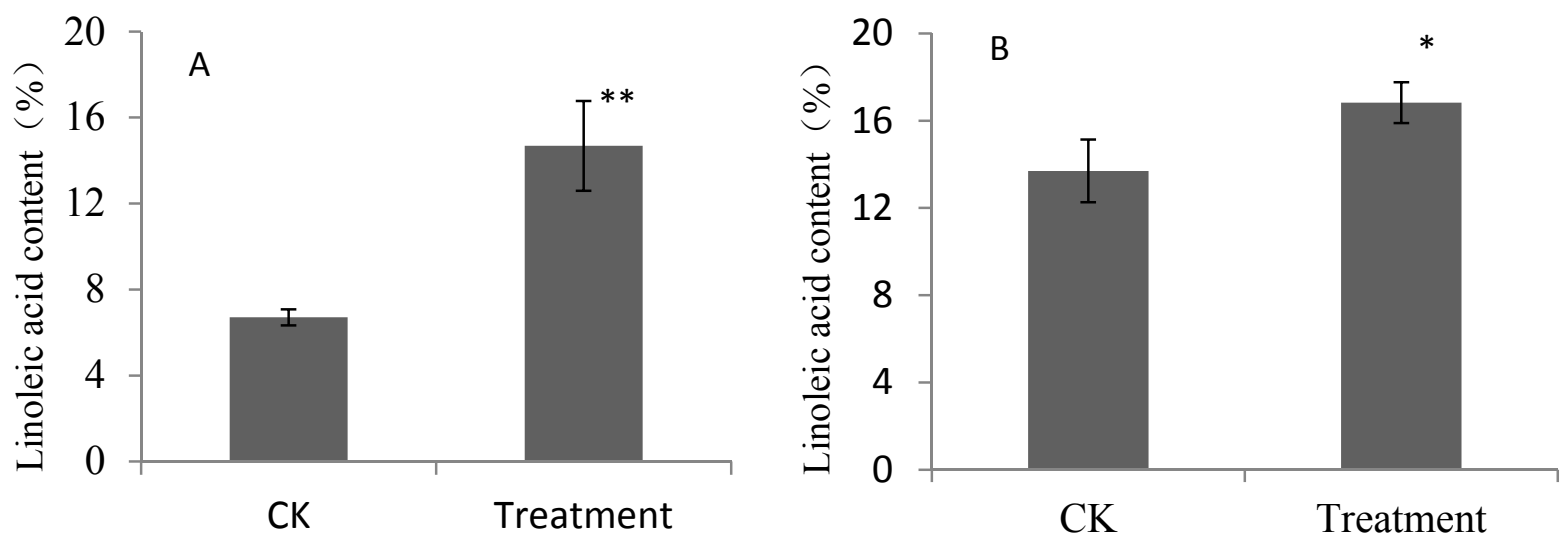

Figure 2. Linolenic acid contents of pear fruits feeding on linolenic acid. (A) P. bretschnrideri "Dangshansuli"; (B) P. ussuriensis "Nanguoli"; Values represented means of three replicates, bar were standard deviation; ** denoted significant difference between treatments and $\mathrm{CK}, p<0.01$.
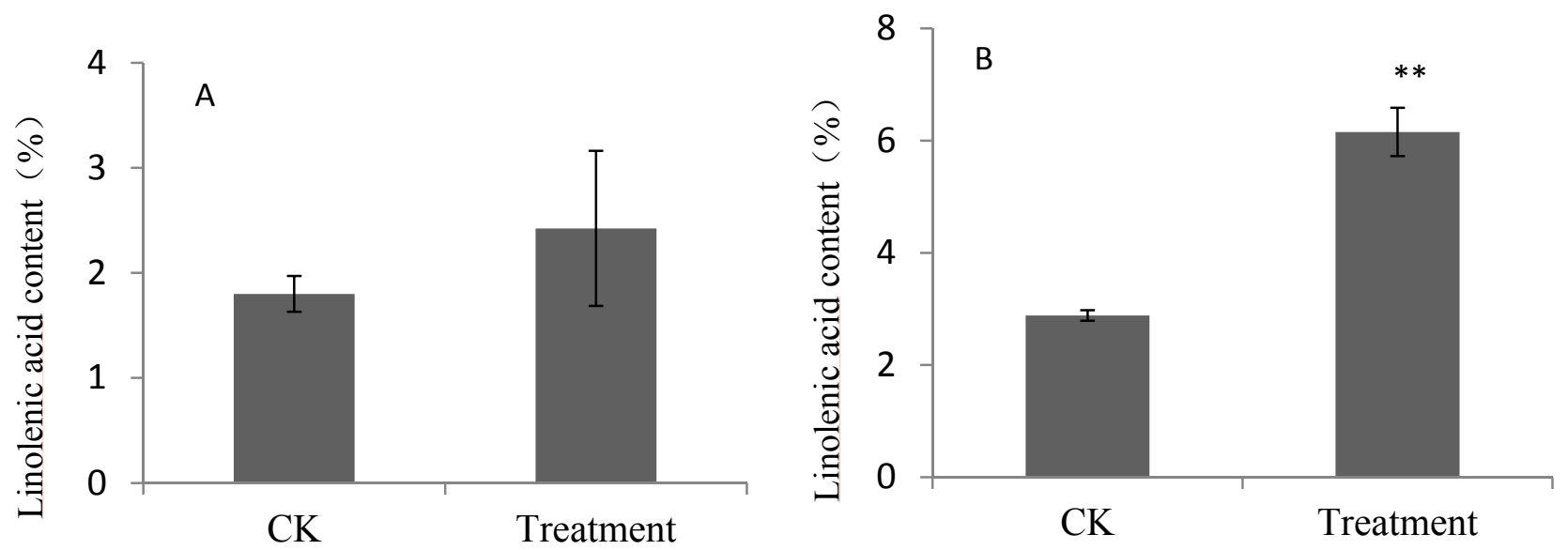

Linoleic acid content increased by 7.98\% and 3.13\% for "Dangshansuli" and "Nanguoli" fruits fed on linoleic acid, respectively. The content of linoleic acid in "Dangshansuli" fruits fed on linoleic acid was 2.19-fold that of the control, while it was 1.23-fold that of the control for "Nanguoli" fruits.

The content of linolenic acid increased for pear fruits fed on linolenic acid, however the increase was not significant for "Dangshansuli" fruits. Linolenic acid content increased by $0.62 \%$ and $3.27 \%$ for "Dangshansuli" and "Nanguoli" fruits fed on linolenic acid, respectively. These results show that 
"Dangshansuli" fruits absorbed linoleic acid much more effectively than linolenic acid, while "Nanguoli" fruits had similar absorption capacities for linolenic acid and linoleic acid.

\subsection{Composition of Aroma Volatiles Derived from Fatty Acid Metabolic Pathway for Pear Fruits} Feeding on Linoleic Acid and Linolenic Acid

The absorbed linoleic acid and linolenic acid were used for the synthesis of straight-chain esters, alcohols and aldehydes. Esters were the class of volatile with the greatest increases in pear fruits. Methyl acetate, methyl hexanoate, methyl 2-hexenoate, ethyl hex-3-enoate, hexyl acetate, and methyl octanoate were all increased in "Dangshansuli" fruits fed on linoleic acid. The esters increased in "Nanguoli" fruits fed on linoleic acid were ethyl acetate, ethyl butanoate, butyl acetate, methyl hexanoate, and some long-chain ester compounds (Table 1). The total quantity of esters increased to $409.4 \mathrm{ng} \cdot \mathrm{g}^{-1} \cdot \mathrm{FW}$ and $1104.4 \mathrm{ng} \cdot \mathrm{g}^{-1} \mathrm{FW}$ for "Dangshansuli" and "Nanguoli" fruits fed on linoleic acid, respectively, representing 2.07-fold and 1.66-fold increases, respectively, over control levels.

Esters were also increased in pear fruits fed on linolenic acid. Methyl acetate, methyl hexanoate, and the unsaturated esters methyl 2-hexenoate, ethyl hex-3-enoate, (Z)-hexen-2-ol acetate, were significantly increased in fruits fed on linolenic acid. More than 10 aroma volatiles, including several long-chain esters were synthesized in pear fruits fed on linolenic acid. The total quantity of esters increased to $285.1 \mathrm{ng} \cdot \mathrm{g}^{-1} \cdot \mathrm{FW}$ and $1,163.4 \mathrm{ng} \cdot \mathrm{g}^{-1} \mathrm{FW}$ for "Dangshanli" and "Nanguoli" fruits fed on linolenic acid, respectively, representing 1.44-fold and 1.75-fold increases over control fruits. The increases in esters corresponded to the increases of linoleic acid and linolenic acid (Figures 1 and 2). The relationships between volatile esters and linoleic acid and linolenic acid, induced by increases in linoleic acid and linolenic acid, or measures promoting their formation, could enhance the volatile esters biosynthesis in fruits.

Volatile esters are formed by esterification of alcohols and acyl from acyl-CoAs in a reaction catalyzed by alcohol acyltransferase (AAT) [14,15]. The concentration of substrates, including alcohols, acyl-CoAs and the precursors of these compounds in fruits, may be a limiting factor for ester production. As demonstrated in the present study, addition of linoleic acid and linolenic acid, which were precursors of many straight-chain alcohols and aldehydes, increased ester production in pear fruits. Previous experiments in apples have shown that off-flavor fruits, such as those harvested prior to reaching maturity or those stored for an extend period of time in low $\mathrm{O}_{2}$ and/or high $\mathrm{CO}_{2}$ environments, immediately produced high amounts of aroma volatiles after feeding on various volatile precursors [5]. These results validated the hypothesis that enhancing levels of linoleic acid and/or linolenic acid in fruits could increase the ester content.

As intermediate of fatty acid metabolism, the direct precursors of ester formation are also affected by the key enzymes catalyzing their production. The activities of these key enzymes may be affected by cultivar, maturity stage, and environmental conditions, either on or off of the plant [16-21]. The greater increase of esters in "Nanguoli" fruits than in "Dangshansuli" fruits fed on the same quantities of linoleic acid and linolenic acid may have been caused by differing enzyme activity in the cultivars. Additionally, (Z)-2-hexenyl acetate was detected only in "Dangshansuli" fruits fed on linolenic acid, ethyl (Z)-4-octenoate was detected only in "Nanguolii" fruits fed on linolenic acid, methyl tetradecanoate was the only ester detected in "Dangshansuli" and "Nanguolii" fruits fed on linolenic acid. The result may due to the specific recognition of key enzymes. 
Table 1. Contents (ng $\left.\cdot \mathrm{g}^{-1} \cdot \mathrm{FW}\right)$ of aroma volatiles derived from fatty acid metabolism for pear fruits feeding on linoleic acid and linolenic acid; (a) -, not detected; (b) Values represented means \pm SD of three replicates; ${ }^{(c)}$ Capitals denoted significant difference in a line for one cultivar at the level of 0.01. Lowercase letters denoted significant differences in a line for one cultivar at the level of 0.05 , according to Duncan's test.

\begin{tabular}{|c|c|c|c|c|c|c|c|}
\hline \multirow{2}{*}{ Kinds } & \multirow{2}{*}{ Aroma Volatiles } & \multicolumn{3}{|c|}{ Dangshansuli } & \multicolumn{3}{|c|}{ Nanguoli } \\
\hline & & CK & Linoleic Acid & Linolenic Acid & CK & Linoleic Acid & Linolenic Acid \\
\hline \multirow{25}{*}{ Esters } & Methyl acetate & - (a) & $15.7 \pm 2.8^{(b)}$ & $14.6 \pm 4.9$ & $5.7 \pm 3.1$ & $17.6 \pm 8.9$ & $10.1 \pm 3.2$ \\
\hline & Ethyl acetate & $45.9 \pm 3.8$ & $50.6 \pm 7.1$ & $55.6 \pm 6.3$ & $185.4 \pm 27.7$ & $324.8 \pm 69.6$ & $263.3 \pm 115.6$ \\
\hline & Ethyl propanoate & - & - & - & $4.4 \pm 1.1$ & $6.8 \pm 1.8$ & $4.4 \pm 1.0$ \\
\hline & Methyl butanoate & $0.9 \pm 0.1$ & $1.8 \pm 0.0$ & $0.7 \pm 0.1$ & $7.4 \pm 1.3$ & $31.5 \pm 18.2$ & $11.1 \pm 2.1$ \\
\hline & Methyl 2-butenoate & - & $0.1 \pm 0.1$ & $0.2 \pm 0.0$ & - & - & - \\
\hline & Ethyl butanoate & $64.3 \pm 8.1$ & $18.7 \pm 3.7$ & $8.8 \pm 5.4$ & $39.6 \pm 13.1$ & $132.1 \pm 2.1$ & $132.8 \pm 11.4$ \\
\hline & Butyl acetate & - & - & - & - & $33.1 \pm 17.2$ & $24.2 \pm 6.3$ \\
\hline & Ethyl 2-butenoate & - & - & - & $6.2 \pm 2.0$ & $7.0 \pm 4.2$ & $4.7 \pm 2.0$ \\
\hline & Ethyl pentanoate & $0.2 \pm 0.0$ & - & - & $0.8 \pm 0.8$ & $0.2 \pm 0.1$ & $2.7 \pm 2.4$ \\
\hline & Pentyl acetate & $1.3 \pm 0.1$ & $7.0 \pm 0.8$ & - & $1.5 \pm 0.5$ & $1.9 \pm 0.8$ & $1.3 \pm 0.9$ \\
\hline & Methyl hexanoate & $1.3 \pm 1.0$ & $54.5 \pm 3.9$ & $31.4 \pm 12.8$ & $33.6 \pm 8.5$ & $231.4 \pm 10.7$ & $130.0 \pm 3.3$ \\
\hline & Methyl 2-hexenoate & $0.5 \pm 0.2$ & $6.8 \pm 0.9$ & $6.7 \pm 3.0$ & $0.3 \pm 0.4$ & $3.0 \pm 1.8$ & $1.5 \pm 1.1$ \\
\hline & Ethyl Hexanoate & $39.2 \pm 5.6$ & $13.1 \pm 11.6$ & $17.3 \pm 10.2$ & $187.2 \pm 37.9$ & $162.7 \pm 15.1$ & $391.2 \pm 10.0$ \\
\hline & Ethyl Hex-3-enoate & - & $21.2 \pm 5.5$ & $43.7 \pm 12.1$ & - & - & - \\
\hline & Hexyl acetate & $39.3 \pm 14.7$ & $165.7 \pm 9.4$ & $26.6 \pm 1.5$ & $168.5 \pm 28.6$ & $118.7 \pm 6.7$ & $136.2 \pm 11.3$ \\
\hline & (Z)-2-Hexenyl acetate & - & - & $48.2 \pm 1.0$ & - & - & - \\
\hline & Methyl heptanoate & - & $8.1 \pm 1.1$ & $3.5 \pm 0.7$ & - & - & - \\
\hline & Ethyl 2-hexenoate & $0.2 \pm 0.0$ & $0.2 \pm 0.1$ & $0.3 \pm 0.1$ & $6.7 \pm 1.9$ & $10.3 \pm 6.5$ & $10.8 \pm 0.1$ \\
\hline & Ethyl heptanoate & $1.5 \pm 0.5$ & - & - & - & - & - \\
\hline & Heptyl acetate & $0.2 \pm 0.1$ & $0.8 \pm 0.5$ & - & $0.2 \pm 0.0$ & - & $1.8 \pm 0.2$ \\
\hline & 3-Hepten-1-ol,1-acetate & - & $0.5 \pm 0.3$ & - & - & - & - \\
\hline & Methyl octanoate & - & $28.8 \pm 2.6$ & $11.3 \pm 1.8$ & - & $9.6 \pm 1.7$ & $5.6 \pm 0.6$ \\
\hline & Methyl (E)-2-octenoate & - & $2.6 \pm 0.5$ & $4.9 \pm 1.2$ & - & $1.5 \pm 0.1$ & - \\
\hline & Ethyl $(Z)$-4-octenoate & - & - & - & - & - & $0.3 \pm 0.1$ \\
\hline & Hexyl butanoate & - & - & - & $0.3 \pm 0.1$ & - & - \\
\hline
\end{tabular}


Table 1. Cont.

\begin{tabular}{|c|c|c|c|c|c|c|c|}
\hline \multirow{2}{*}{ Kinds } & \multirow{2}{*}{ Aroma Volatiles } & \multicolumn{3}{|c|}{ Dangshansuli } & \multicolumn{3}{|c|}{ Nanguoli } \\
\hline & & CK & Linoleic Acid & Linolenic Acid & CK & Linoleic Acid & Linolenic Acid \\
\hline \multirow{12}{*}{ Esters } & Ethyl octanoate & $3.1 \pm 0.6$ & $0.6 \pm 0.0$ & - & $2.2 \pm 1.1$ & $0.9 \pm 0.2$ & $1.8 \pm 0.2$ \\
\hline & Methyl nonanoate & - & $0.3 \pm 0.1$ & $0.4 \pm 0.0$ & - & - & - \\
\hline & Ethyl $(E)$-2-octenoate & - & - & - & $1.7 \pm 0.8$ & $1.4 \pm 0.1$ & $3.9 \pm 0.1$ \\
\hline & Methyl 4-decenoate & - & $2.2 \pm 0.3$ & $1.8 \pm 0.8$ & - & $1.0 \pm 0.2$ & - \\
\hline & Methyl decanoate & - & $1.0 \pm 0.0$ & $1.3 \pm 0.4$ & - & - & - \\
\hline & Hexyl hexanoate & - & $0.5 \pm 0.1$ & $0.4 \pm 0.1$ & - & - & - \\
\hline & Methyl $(E, Z)-2,4$-decadienoate & - & $5.4 \pm 0.9$ & $3.6 \pm 1.0$ & $2.8 \pm 1.5$ & $3.4 \pm 0.2$ & $8.5 \pm 1.3$ \\
\hline & Ethyl $(E, Z)$-2,4-decadienoate & - & $0.9 \pm 0.2$ & $1.2 \pm 0.4$ & $9.6 \pm 4.1$ & $5.5 \pm 1.2$ & $19.0 \pm 1.2$ \\
\hline & Methyl dodecanoate & - & $0.6 \pm 0.1$ & $0.8 \pm 0.1$ & - & - & $1.2 \pm 0.3$ \\
\hline & Methyl tetradecanoate & - & - & $0.1 \pm 0.0$ & - & - & $0.5 \pm 0.1$ \\
\hline & Methyl hexadecanoate & - & $1.8 \pm 0.7$ & $1.7 \pm 0.2$ & - & - & - \\
\hline & Subtotal & $197.9^{\mathrm{cC},(\mathrm{c})}$ & $409.4^{\mathrm{aA}}$ & $285.1^{\mathrm{bB}}$ & $664.1^{\mathrm{bB}}$ & $1104.4^{\mathrm{aA}}$ & $1163.4^{\mathrm{aA}}$ \\
\hline \multirow{5}{*}{ Aldehydes } & Hexanal & $16.7 \pm 2.1$ & $9.2 \pm 1.6$ & $3.7 \pm 4.0$ & $131.7 \pm 23.1$ & $44.1 \pm 3.1$ & $4.3 \pm 0.6$ \\
\hline & 2-Hexenal & $8.1 \pm 2.6$ & $2.6 \pm 0.1$ & $9.0 \pm 7.0$ & - & - & - \\
\hline & Nonanal & $2.2 \pm 0.4$ & $0.5 \pm 0.1$ & $1.6 \pm 0.4$ & - & - & - \\
\hline & Decanal & $0.9 \pm 0.1$ & - & - & - & - & - \\
\hline & Subtotal & $27.9^{\mathrm{aA}}$ & $12.3^{\mathrm{bB}}$ & $14.3^{\mathrm{bAB}}$ & $131.7^{\mathrm{aA}}$ & $44.1^{\mathrm{bB}}$ & $4.3^{\mathrm{cC}}$ \\
\hline \multirow{8}{*}{ Alcohols } & Ethanol & $5.5 \pm 1.7$ & $3.1 \pm 0.9$ & $5.0 \pm 2.0$ & $7.8 \pm 2.3$ & $14.4 \pm 0.1$ & $18.1 \pm 5.5$ \\
\hline & (E)-2-Hexen-1-ol & $0.2 \pm 0.1$ & $2.4 \pm 0.2$ & $10.2 \pm 1.7$ & - & $2.6 \pm 0.2$ & $1.7 \pm 0.2$ \\
\hline & 1-Hexanol & $1.9 \pm 1.3$ & $86.9 \pm 1.4$ & $23.6 \pm 3.3$ & $33.3 \pm 3.3$ & $139.5 \pm 1.2$ & $4.9 \pm 3.2$ \\
\hline & 1-Heptanol & - & $3.2 \pm 1.6$ & - & - & - & - \\
\hline & Octen-2-ol & - & $4.4 \pm 0.7$ & - & - & - & - \\
\hline & 1-Octanol & $0.3 \pm 0.0$ & $1.9 \pm 0.5$ & $0.5 \pm 0.1$ & $0.7 \pm 0.2$ & $0.8 \pm 0.1$ & $1.2 \pm 0.1$ \\
\hline & (E)-2-Octen-1-ol & - & $1.7 \pm 0.0$ & - & - & - & - \\
\hline & Subtotal & $7.9^{\mathrm{cC}}$ & $103.6^{\mathrm{aA}}$ & $39.3^{\mathrm{bB}}$ & $41.9^{\mathrm{bB}}$ & $157.3^{\mathrm{aA}}$ & $25.9^{\mathrm{cB}}$ \\
\hline
\end{tabular}


The different characters of the key enzymes and the different content of linoleic acid and linolenic acid maybe explain the varying volatile ester-forming capacities in different pear cultivars. The enhancement of precursor contents may be a more feasible method of increasing volatile esters in pear fruits for a cultivar. The content of alcohols also changed significantly. The main alcohols increased in "Dangshansuli" fruits were (E)-2-hexen-1-ol, 1-hexanol, 1-heptanol, 1-octanol and octen-2-ol, while 1-hexanol and 1-octanol increased in "Nanguoli" fruits. The total quantity of alcohol was increased for pear fruits fed on linoleic acid, while the increase was greater for "Dangshansuli" than "Nanguoli" fruits. The total quantity of alcohol was increased in "Dangshansuli" fruits fed on linolenic acid, but decreased in "Nanguoli" fruits given this compound. The contents of aldehydes were decreased in pear fruits fed on linoleic acid and linolenic acid.

\subsection{Contents of Hexanal and Hexanol for Pear Fruits Fed on Hexanal and Hexanol}

The contents of hexanol and hexanal were significantly increased in pear fruits fed on hexanol and hexanal (Table 2). This result indicated hexanol and hexanal could be efficiently absorbed by pear fruits. The content of hexanol in "Nanguoli" fruits was similar to that in "Dangshansuli" fruits when fed the same quantity of hexanal, while the content of hexanol in "Nanguoli" fruits was higher than that in "Dangshansuli" fruits when fed the same quantity of hexanol. The content of hexanol was significant greater than that of hexanal in pear fruits fed on hexanal or hexanol.

Table 2. Hexanol and hexanal contents $\left(\mathrm{ng}^{-} \mathrm{g}^{-} 1 \cdot \mathrm{FW}\right)$ of pear fruits fed on hexanol

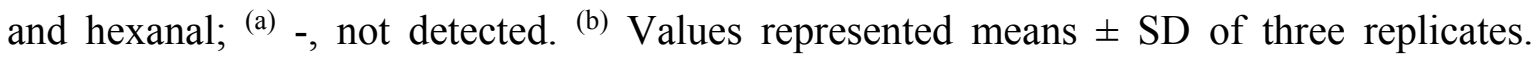
(c) ** denoted significant differences between treatments and $\mathrm{CK}$ at the level of 0.01 , according to Duncan's test.

\begin{tabular}{ccccc}
\hline \multirow{2}{*}{ Treatments } & \multicolumn{2}{c}{ Dangshansuli } & \multicolumn{2}{c}{ Nanguoli } \\
\cline { 2 - 5 } & Hexanal & Hexanol & Hexanal & Hexanol \\
\hline CK & $16.7 \pm 2.1^{\text {(b) }}$ & $1.9 \pm 1.3$ & - (a) $^{* *}$ & $37.9 \pm 10.0$ \\
Hexanal & $19.0 \pm 0.2$ & $1909.3 \pm 39.8^{* *(c)}$ & $19.7 \pm 10.3 * *$ & $1822.4 \pm 748.1 * *$ \\
Hexanol & $20.3 \pm 0.3$ & $2193.9 \pm 47.8^{* *}$ & $11.0 \pm 15.6^{* *}$ & $3024.8 \pm 537.3 * *$ \\
\hline
\end{tabular}

\subsection{Hexyl Ester and/or Hexanoate Ester Content in Pear Fruits Fed on Hexanal and Hexanol}

Hexanol and hexanal are important intermediates of the fatty acid metabolic pathway. Some of the hexanol and hexanal in fruits shuttle across cell membranes and alter fruit aroma volatiles, while the others are used as precursors for ester formation. Hexanol can be directly used to synthesis volatile esters catalyzed by AAT. Hexanal, as an intermediate metabolite, is another important substrate of volatile esters biosynthesis. As the reduced form of hexanal, hexanol can be used in the syntheses of hexyl esters. Similarly, as the oxidized form of hexanal, hexanoate can be used to form hexanoate esters.

The content of hexyl ester and hexanoate ester were increased in pear fruits feeding on hexanal and hexanol due to the increase in precursor substrates of ester biosynthesis (Table 3). Hexyl esters content, especially those of hexyl acetate, hexyl butanoate, and hexyl hexanoate, were significantly increased in pear fruits fed on hexanol. The total quantity of hexyl ester reached $1524.2 \mathrm{ng} \cdot \mathrm{g}^{-1} \mathrm{FW}$ and $1127.4 \mathrm{ng} \cdot \mathrm{g}^{-1} \mathrm{FW}$ for "Dangshansuli" and "Nanguoli" fruits fed on hexanol, respectively. These values represented increases 
of $1485.1 \mathrm{ng} \cdot \mathrm{g}^{-1} \mathrm{FW}$ and $958.6 \mathrm{ng} \cdot \mathrm{g}^{-1} \mathrm{FW}$, separately, over the control fruits. The greater increases of hexyl ester content in "Dangshansuli" fruits than "Nanguoli" fruits fed on the same quantity of hexanol demonstrated that "Dangshansuli" fruits were capable of forming more hexyl ester than "Nanguoli" fruits when given sufficient hexanol.

Table 3. Hexyl and hexanoate esters contents $\left(\mathrm{ng} \cdot \mathrm{g}^{-1} \cdot \mathrm{FW}\right)$ of pear fruits feeding on hexanol and hexanal ${ }^{(a)}$-, not detected; ${ }^{\text {(b) }}$ Values represented means of three replicates; ${ }^{(c)}$ Capitals denoted significant differences in a line for one cultivar at the level of 0.01 . Lowercase denoted significant differences in lines for one cultivar at the level of 0.05 .

\begin{tabular}{|c|c|c|c|c|c|c|}
\hline \multirow{2}{*}{ Aroma Volatiles } & \multicolumn{3}{|c|}{ Dangshansuli } & \multicolumn{3}{|c|}{ Nanguoli } \\
\hline & CK & Hexanal & Hexanol & CK & Hexanal & Hexanol \\
\hline Methyl hexanoate & $1.3 \pm 1.0 \mathrm{bAB}^{(\mathrm{b})}$ & $5.4 \pm 4.2 \mathrm{aA}$ & - (a) & $33.6 \pm 8.5 \mathrm{bB}$ & $81.0 \pm 24.6 \mathrm{aA}$ & $25.8 \pm 1.82 \mathrm{bB}$ \\
\hline Ethyl hexanoate & $39.2 \pm 5.6 \mathrm{cC}$ & $526.0 \pm 22.9 \mathrm{bB}$ & $114.6 \pm 4.8 \mathrm{aA}$ & $187.2 \pm 37.9 \mathrm{bB}$ & $621.5 \pm 226.4 \mathrm{aA}$ & $160.5 \pm 76.0 \mathrm{bB}$ \\
\hline Hexyl acetate & $39.3 \pm 14.7 \mathrm{bB}$ & $1370.4 \pm 162.9 \mathrm{aA}$ & $1350.2 \pm 284.8 \mathrm{aA}$ & $168.5 \pm 28.6 \mathrm{cB}$ & $594.3 \pm 303.8 \mathrm{bAB}$ & $1006.1 \pm 71.1 \mathrm{aA}$ \\
\hline Hexyl butanoate & - & $72.4 \pm 4.3 \mathrm{aA}$ & $50.0 \pm 24.1 \mathrm{bA}$ & $0.3 \pm 0.1 \mathrm{cC}$ & $35.0 \pm 10.9 \mathrm{bB}$ & $79.7 \pm 19.0 \mathrm{aA}$ \\
\hline Hexyl hexanoate & - & $272.6 \pm 79.9 \mathrm{aA}$ & $120.7 \pm 38.2 \mathrm{bB}$ & - & $137.7 \pm 42.9 \mathrm{aA}$ & $41.6 \pm 58.9 \mathrm{bB}$ \\
\hline Hexyl benzoate & - & $0.5 \pm 0.1 \mathrm{bB}$ & $1.3 \pm 0.4 \mathrm{aA}$ & - & - & - \\
\hline Hexyl octanoate & - & $0.9 \pm 0.2 \mathrm{bB}$ & $2.2 \pm 1.0 \mathrm{aA}$ & - & - & - \\
\hline Total contents & $79.8 \pm 21.2 \mathrm{cC}^{(\mathrm{c})}$ & $2248.2 \pm 274.6 \mathrm{aA}$ & $1639.0 \pm 353.2 \mathrm{bB}$ & $389.60 \pm 75.1 \mathrm{bB}$ & $1469.5 \pm 608.6 \mathrm{aA}$ & $1313.8 \pm 153.9 \mathrm{aA}$ \\
\hline
\end{tabular}

The dominant esters for pear fruits fed on hexanal were hexyl acetate and ethyl hexanoate, followed by hexyl hexanoate. The content of hexyl acetate in 'Dangshansuli' fruits fed on hexanal was 2.6-fold that of ethyl hexanoate, while the contents of ethyl hexanoate and hexyl acetate were similar in "Nanguoli" fruits fed on hexanal. The total quantity of hexanoate esters was $804.0 \mathrm{ng} \cdot \mathrm{g}^{-1} \cdot \mathrm{FW}$ and $840.2 \mathrm{ng} \cdot \mathrm{g}^{-1} \cdot \mathrm{FW}$, respectively, for "Dangshansuli" and "Nanguoli" fruits fed on the same quantity of hexanal, representing increases of $759.5 \mathrm{ng} \cdot \mathrm{g}^{-1} \cdot \mathrm{FW}$ and $619.4 \mathrm{ng} \cdot \mathrm{g}^{-1} \cdot \mathrm{FW}$. The content of hexyl esters were $1716.8 \mathrm{ng} \cdot \mathrm{g}^{-1} \cdot \mathrm{FW}$ and $767.0 \mathrm{ng} \cdot \mathrm{g}^{-1} \cdot \mathrm{FW}$ for "Dangshansuli" and "Nanguoli" fruits fed on the same quantity of hexanal, representing increases of $1677.5 \mathrm{ng} \cdot \mathrm{g}^{-1} \cdot \mathrm{FW}$ and $598.2 \mathrm{ng} \cdot \mathrm{g}^{-1} \cdot \mathrm{FW}$, respectively. Thus, we concluded that the greater amount of hexanal absorbed by "Dangshansuli" fruits was reduced to hexanol for the synthesis hexyl esters, but not oxidized to hexanoate for the synthesis hexanoate esters, while similar quantities of hexanol and hexanoate were formed to generate the corresponding esters in "Nanguoli" fruits fed on hexanal.

The increase of hexanol in "Nanguoli" fruits was higher than that in "Dangshansuli" fruits when they were fed on the same quantity of hexanol (Table 2). However, the content of the corresponding hexyl esters in "Nanguoli" fruits was two-thirds that in "Dangshansuli" fruits (Table 3). The comparatively low hexyl esters content in "Nanguoli" fruit fed on hexanol have been due to the greater released from fruits or unknown differences in the capacity for ester formation between cultivars remained unknown. If it was the metabolic difference, the difference may be due to the low levels of acetate or decreased enzyme activity for ester synthesis, as well as feedback inhibition. Feedback inhibition of volatile aroma biosynthesis has been observed in Antirrhinum majus [22]. Whether the low hexyl acetate formation for "Nanguoli" fruits fed on hexanol resulted from decreased AAT activity in vitro or feedback inhibition requires further analysis. 
Different increases of hexyl esters were observed in different pear fruits feeding on same quantity of hexanal. Higher levels of hexyl ester in "Dangshansuli" fruits showed that more hexanol was formed in "Dangshansuli" fruits after feeding on hexanal. The activity levels of reductase/oxidase were responsible for the aroma volatiles synthesis. In "Dangshansuli" fruits, more hexanal was reduced to hexanol catalyzed by $\mathrm{ADH}$ reductase, so the activity of $\mathrm{ADH}$ reductase may not the limiting factor in volatile ester biosynthesis for these fruits. The low levels of hexyl esters in "Nanguoli" fruits fed on hexanal indicated the limitation of ADH reductase in catalyzing hexanal to hexanol. That ADH reductase was a limiting factor for aroma biosynthesis in "Nanguoli" fruits remains a hypothesis and requires further study.

The higher ester content in pear fruits fed on hexanal and hexanol than fruits fed on linoleic acid and linolenic acid showed that the former two compounds more efficiently enhanced volatile biosynthesis, which may have been due to comparatively better uptake and metabolism of these compounds. A similar phenomenon has been observed in branched chain flavor volatile synthesis by amino acid metabolism pathway. The application of amino acid to fruit pericarp segments did not stimulate synthesis of the corresponding volatile, however application of the corresponding $\alpha$-keto acids resulted in much higher volatile production [23]. Therefore, the content of hexanal and hexanol or the formation rate are likely more important in the production of aroma volatiles than linoleic acid and linolenic acid. Metabolic intermediates have been indicated as more important than precursors in aroma compound synthesis for other fruits [13]. Due to the importance of the precursors hexanal and hexanol, the initial steps (including those catalyzed by the key enzymes LOX and HPL) of hexanal and hexanol formation are critical for ester biosynthesis in pear fruits. In plants, hexanal is synthesized through the conversion of linolenic acid or linoleic acid via the enzymes LOX and HPL. Synthesis of green note aroma compounds through the biotransformation of fatty acids using yeast cells co-expressing lipoxygenase and hydroperoxide lyase indicates that modification of LOX and HPL activity may serve as a promising approach for increasing efficiency of green note aldehyde synthesis [24]. Several studies have demonstrated that LOX plays a key role in volatile ester production [16-18]. Accordingly, further studies of HPL and ADH, which catalyze aldehydes to their corresponding alcohols in pear fruits, should be taken.

\section{Experimental Section}

\subsection{Plant Materials}

In this study, "Pyrus bretschnrideri" "Dangshansuli" and "Pyrus ussuriensis" "Nanguoli" fruits of the same age and grown under the similar cultivation measures, including irrigation and fertilization, were acquired from the Liaoning Institute of Pomology (Xiongyue, China). Twenty ripe fruits of uniform size and color and free of visible defects or decay were harvested for each cultivar and stored under refrigeration.

\subsection{Precursor Substrates and Incubation Method}

Each precursor standard (linoleic acid, linolenic acid, hexanal and hexanol) was dissolved in $0.4 \mathrm{mM}$ sorbitol, and several drops of Tween-20 were added to promote dissolution. Individual $1 \mathrm{mM}$ solutions of linoleic acid, linolenic acid, hexanal and hexanol solution were obtained individually for incubation 
in this study. Linoleic acid, linolenic acid, hexanal and hexanol standards were all of analytical grade and purchased from Sigma-Aldrich (St. Louis, MO, USA). Sorbitol was chemically pure and purchased from Sinopharm Chemical Reagent Co., Ltd (Shanghai, China). Fruits were removed from cold storage and incubated at room temperature for $24 \mathrm{~h}$, then cut into discs with a diameter of $1 \mathrm{~cm}$ and a thickness of $0.2 \mathrm{~cm}$. Incubation of fruits with the precursor substrates was conducted as described by Zhang [25]. Fruit discs were divided into five portions. The first portion was placed in $0.4 \mathrm{mM}$ sorbitol and used for a control $(\mathrm{CK})$, the other portions were placed into the different substrate solutions and incubated for $8 \mathrm{~h}$ at $35^{\circ} \mathrm{C}$ while shaking at $60 \mathrm{r} \cdot \mathrm{min}^{-1}$. After incubation, the discs were blotted using a filter paper, frozen in liquid nitrogen, and stored at $-80{ }^{\circ} \mathrm{C}$ until analysis.

\subsection{Extraction of Polar Lipids}

Fruit tissue $(2 \mathrm{~g})$ was ground in an ice bath and chloroform/methanol $(6 \mathrm{~mL}, 1: 2, \mathrm{v} / \mathrm{v})$ was added in the flesh. The tissue was extracted for $20 \mathrm{~min}$ at $4{ }^{\circ} \mathrm{C}$, then centrifuged at $3000 \times g$ for $7 \mathrm{~min}$. The resulting extract was again subjected to extraction with chloroform/methanol ( $3 \mathrm{~mL}, 1: 2, \mathrm{v} / \mathrm{v})$ and chloroform $(4 \mathrm{~mL})$ was then used to purge. All of the resultant extracts were combined, $0.76 \% \mathrm{NaCl}(\mathrm{w} / \mathrm{v})(20 \mathrm{~mL})$ was added, and the samples were shaken on a shaking table (WZS-200A, Selon Scientific Instrument Co., Ltd., Shanghai, China) for $15 \mathrm{~min}$. The aqueous layer was removed and the residue was vaporized using a rotary evaporator (RE-3000, Shanghai Yarong Instrument Factory, Shanghai, China) to obtain the polar lipids. The polar lipids were dissolved in petroleum ether $\left(90-120^{\circ} \mathrm{C}\right.$ boiling point range) with saturated methanol $(6 \mathrm{~mL})$, and methanol saturated with petroleum ether $(6 \mathrm{~mL})$ was then used to purify them. This purification process was repeated three times. Finally, the pure polar lipid was dissolved in methanol (2 mL, gas chromatography (GC) grade) for esterification.

The polar lipids were then methyl esterified. The polar lipid was redissolved in $0.4 \mathrm{M} \mathrm{KOH}$ in methanol $(2 \mathrm{~mL})$ and benzene-petroleum ether $\left(30-60{ }^{\circ} \mathrm{C}\right.$ boiling point range, $\left.2 \mathrm{~mL}, 1: 1, \mathrm{v} / \mathrm{v}\right)$, vibrated, and then allowed to rest for $15 \mathrm{~min}$. Distilled water $(16 \mathrm{~mL})$ was added to the vials, and the upper layer of the extracts was withdrawn and vaporized using a vacuum machine, and then redissolved in hexane $(1 \mathrm{~mL})$ for gas chromatography analysis.

\subsection{Analysis of Fatty Acid by GC}

Fatty acids were analyzed using an Agilent 7820 gas chromatograph (Santa Clara, CA, USA) equipped with flame ionization detector (FID) detector and DB-WAX column, $(30 \mathrm{~cm} \times 0.25 \mathrm{~mm} \times 0.25 \mu \mathrm{m}$, Agilent). A volume of $5 \mu \mathrm{L}$ of extract was injected for analyses. Helium was used as the carrier gas $\left(1.0 \mathrm{~mL} \cdot \mathrm{min}^{-1}\right)$ in constant flow mode, with a split ratio of $1: 10$. Injector and detector temperatures were set at $250{ }^{\circ} \mathrm{C}$ and $280{ }^{\circ} \mathrm{C}$, respectively. For the temperature gradient, the oven was set at an initial temperature of $50{ }^{\circ} \mathrm{C}$ for $1 \mathrm{~min}$, which was increased to $200{ }^{\circ} \mathrm{C}$ at a rate of $25^{\circ} \mathrm{C} \cdot \mathrm{min}^{-1}$, then raised to $230^{\circ} \mathrm{C}$ at a rate of $3{ }^{\circ} \mathrm{C} \cdot \mathrm{min}^{-1}$, and held at $230^{\circ} \mathrm{C}$ for $18 \mathrm{~min}$.

\subsection{Identification and Quantification of Fatty Acids}

Fatty acids were identified using fatty acid methyl ester mixture (FAME, C4-C24, Sigma), and quantified using normalization methods. Fatty acid content is denoted as a percent. 


\subsection{Extraction and Concentration of Aroma Volatile of Pear Fruits}

Head space solid-phase microextraction (HS-SPME) was used to extract and concentrate the aroma volatiles as described by Qin [26]. The volatiles were fused with silica fiber coated with $65 \mu \mathrm{m}$ of polydimethylsiloxane-divinylbenzene (65 $\mu \mathrm{m}$ of PDMS/DVB; Supelco Co., Bellefonte, PA, USA). Next, fruit tissue $(10.0 \mathrm{~g})$ was placed into a $20 \mathrm{~mL}$ screw-cap vial containing $\mathrm{NaCl}$ (3.6 g, to facilitate the release of volatile compounds) and $0.04 \mathrm{~g} \cdot \mathrm{mL}^{-1}$ 3-nonanone $(50 \mu \mathrm{L}$, used as an internal standard). The SPME fiber was exposed to the head space of the sample for $30 \mathrm{~min}$ to adsorb the analyte, then introduced into the heated injector port of the chromatography apparatus for desorption at $250{ }^{\circ} \mathrm{C}$ for 5 min in splitless mode.

\subsection{GC-Mass Spectrometry (MS) Analysis of Aroma Volatiles}

Volatile constituents were analyzed using an Agilent 5973B mass selective detector coupled to an Agilent 7890A gas chromatograph equipped with a $30 \mathrm{~m} \times 0.25 \mathrm{~mm} \times 1.0 \mathrm{~mm} \mathrm{HP}-5 \mathrm{MS}$ (5\% phenyl-polymethylsiloxane) capillary column. A constant column flow of $1.0 \mathrm{~mL} / \mathrm{min}$ helium was used as carrier gas. The injector and detector temperatures were $250{ }^{\circ} \mathrm{C}$ and $280{ }^{\circ} \mathrm{C}$, respectively. The oven temperature program was $35^{\circ} \mathrm{C}$ for $8 \mathrm{~min}$, an increase of $2^{\circ} \mathrm{C} / \mathrm{min}$ to $140{ }^{\circ} \mathrm{C}, 140{ }^{\circ} \mathrm{C}$ for $2 \mathrm{~min}$, and an increase of $10{ }^{\circ} \mathrm{C} / \mathrm{min}$ to $260^{\circ} \mathrm{C}$, which was held for $5 \mathrm{~min}$. Mass spectra were recorded at $70 \mathrm{eV}$ in electron impact (EI) ionization mode. The temperatures of the quadrupole mass detector and ion source were $150{ }^{\circ} \mathrm{C}$ and $230{ }^{\circ} \mathrm{C}$, respectively. The temperature of the transfer line was $280{ }^{\circ} \mathrm{C}$. Mass spectra were scanned in the $\mathrm{m} / \mathrm{z}$ range 33-350 amu at intervals of $1 \mathrm{~s}$.

\subsection{Identification and Quantification of Aroma Volatiles}

Tentative identification of aroma volatiles was conducted by comparing the mass spectra of the samples with the data system library (NIST 98). Whenever possible, MS identification was confirmed using authentic references for ethyl acetate, butyl acetate, ethyl hexanoate, hexyl acetate, ethyl octanoate, ethyl (E,Z)-2,4-decadienoate, 1-hexanol and hexanal were used in the experiment. Quantification was conducted using the internal standard method, where the concentration of each aroma volatile was normalized to that of 3-nonanone.

\subsection{Statistical Analysis}

The SPSS 16.0 statistical software package (IBM, Armonk, NY, USA) and Excel were used for statistical analysis. All data were generated from triplicate experiments and reported as the average of three replicates. Analysis of variance (ANOVA) was calculated and the significance of differences was detected by using Duncan's test or Tukey's test.

\section{Conclusions}

Aroma volatiles, particularly volatile esters, were significantly increased both qualitatively and quantitatively in pear fruits fed on fatty acid metabolic precursors. The quantity of aroma volatiles was largely dependent on the quantity of precursors presented. Hexanal and hexanol were more efficient for 
promoting volatile synthesis than linoleic acid and linolenic acid. More volatile esters were synthesized by "Dangshansuli" fruits than by "Nanguoli" fruits fed on the same quantity of hexanal and hexanol, suggesting that the green-flavored "Dangshansuli" fruits had less endogenous hexanal and hexanol to form volatile esters. Hexanal and hexanol contents and their formation rates may be rate-limiting factors for volatile ester production in pear fruits.

\section{Acknowledgments}

This study was supported financially by the National Natural Science Foundation of China (31230063 and 31301739) and the National High Technology Research and Development Program of China ('863' Program, grant no.2011AA10020601).

\section{Author Contributions}

Shaoling Zhang, Gaihua Qin and Yiliu Xu designed the experiment; Gaihua Qin, Shutian Tao, Huping Zhang and Wenjiang Huang did the experiments; Gaihua Qin and Juyou Wu wrote the paper.

\section{Conflicts of Interest}

The authors declare no conflict of interest.

\section{References}

1. Bartley, I.M.; Stoker, P.G.; Martin, A.D.E.; Hatfield, S.G.S.; Knee, M. Synthesis of aroma compounds by apples supplied with alcohols and methyl esters of fatty acids. J. Sci. Food Agric. 1985, 36, 567-574.

2. Fellman, J.K.; Miller, T.W.; Mattinson, D.S.; Mattheis, J.P. Factors that influence biosynthesis of volatile flavor compounds in apple fruits. Hortiscience 2000, 35, 1026-1033.

3. Song, J.; Bangerth, F. Fatty acids as precursors for aroma volatile biosynthesis in pre-climacteric and climacteric apple fruit. Postharvest Biol. Technol. 2003, 30, 113-121.

4. Wang, C.L.; Xing, J.S.; Chin, C.K.; Ho, C.T.; Martin, C.E. Modification of fatty acids changes the flavor volatiles in tomato leaves. Phytochemistry 2001, 58, 227-232.

5. Bangerth, F.; Streif, J.; Song, J.; Brackmann, A. Investigations into the physiology of volatile aroma production of apple fruits. Acta Hortic. 1996, 464, 189-194.

6. Brackmann, A.; Streif, J.; Bangerth, F. Relationship between a reduced aroma production and lipid metabolism of apples after long-term controlled-atmosphere storage. J. Am. Soc. Hortic. Sci. 1993, $118,243-247$.

7. Harb, J.; Streif, J.; Bangerth, F. Response of controlled atmosphere (CA) stored 'Golden Delicious' apples to the treatments with alcohols and aldehydes as aroma precursors. Gartenbauwissenschaft 2000, 65, 154-161.

8. Kollmannsberger, H.; Berger, R. Precursor atmosphere storage induced flavour changes in apples cv. Red Delicious. Chem. Mikrobiol. Technol. Lebensm. 1992, 14, 81-86.

9. Chen, J.L.; Zhou, S.;Yan, S.J.; Ma, Y.K.; Hu, X.S. Analysis of Aroma Components of Fengshui Dangshan and Nanguo Pear by SPME/GC/MS. Acta Hortic. Sin. 2005, 32, 301-303. 
10. Schwab, W.; Davidovich-Rikanati, R.; Lewinsohn, E. Biosynthesis of plant-derived flavor compounds. Plant J. 2008, 54, 712-732.

11. Pérez, A.G.; Olías, R.; Olías, J.M.; Sanz, C. Biosynthesis of 4-hydroxy-2,5-dimethyl-3 (2 H)-furanone and derivatives in in vitro grown strawberries. J. Agric. Food Chem. 1999, 47, 655-658.

12. Roscher, R.; Schreier, P.; Schwab, W. Metabolism of 2,5-dimethyl-4-hydroxy-3 (2 H)-furanone in detached ripening strawberry fruits. J. Agric. Food Chem. 1997, 45, 3202-3205.

13. Gonda, I.; Bar, E.; Portnoy, V.; Lev, S.; Burger, J.; Schaffer, A.A.; Tadmor, Y.; Gepstein, S.; Giovannoni, J.J.; Katzir, N.; et al. Branched-chain and aromatic amino acid catabolism into aroma volatiles in Cucumis melo L. fruit. J. Exp. Bot. 2010, 61, 1111-1123.

14. Pérez, A.G.; Sanz, C.; Olías, R.; Ríos, J.J.; Olías, J.M. Evolution of strawberry alcohol acyltransferase activity during fruit development and storage. J. Agric. Food Chem. 1996, 44, 3286-3290.

15. Perez, A.G.; Olías, R.; Espada, J.; Olías, J.M.; Sanz, C. Rapid determination of sugars, nonvolatile acids, and ascorbic acid in strawberry and other fruits. J. Agric. Food Chem. 1997, 45, 3545-3549.

16. Altisent, R.; Graell, J.; Lara, I.; López, L.; Echeverría, G. Increased straight-chain esters content after ultra low oxygen storage and its relation to the lipoxygenase system in 'Golden Reinders ${ }^{\circledR}$, apples. Eur. Food. Res. Technol. 2010, 232, 51-61.

17. Lara, I.; Echeverría, G.; Graell, J.; López, M.L. Volatile emission after controlled atmosphere storage of Mondial Gala apples (Malus domestica): Relationship to some involved enzyme activities. J. Agric. Food Chem. 2007, 55, 6087-6095.

18. Altisent, R.; Echeverría, G.; Graell, J.; López, L.; Lara, I. Lipoxygenase activity is involved in the regeneration of volatile ester-synthesizing capacity after ultra-low oxygen storage of 'Fuji' apple. J. Agric. Food Chem. 2009, 57, 4305-4312.

19. Zhang, B.; Yin, X.R.; Shen, J.Y.; Chen, K.S.; Ferguson, I.B. Volatiles production and lipoxygenase gene expression in kiwifruit peel and flesh during fruit ripening. J. Am. Soc. Hortic. Sci. 2009, 134, 472-477.

20. Leone, A.; Bleve-Zacheo, T.; Gerardi, C.; Melillo, M.T.; Leo, L.; Zacheo, G. Lipoxygenase involvement in ripening strawberry. J. Agric. Food Chem. 2006, 54, 6835-6844.

21. Defilippi, B.G.; Dandekar, A.M.; Kader, A.A. Relationship of ethylene biosynthesis to volatile production, related enzymes, and precursor availability in apple peel and flesh tissues. J. Agric. Food Chem. 2005, 53, 3133-3141.

22. Tholl, D.; Kish, C.M.; Orlova, I.; Sherman, D.; Gershenzon, J.; Pichersky, E.; Dudareva, N. Formation of monoterpenes in Antirrhinum majus and Clarkia breweri flowers involves heterodimeric geranyl diphosphate synthases. Plant. Cell 2004, 16, 977-992.

23. Kochevenko, A.; Araujo, L.; Maloney, G.S.; Tiemam, T.M.; Do, P.T.; Taylor, M.G.; Klee, H.J.; Fernie, A.R. Catabolism of branched chain amino acids supports respiration but not volatile synthesis in tomato fruits. Mol. Plant. 2012, 5, 366-375.

24. Buchhaupt, M.; Guder, J.C.; Etschmann, M.M.; Schrader, J. Synthesis of green note aroma compounds by biotransformation of fatty acids using yeast cells coexpressing lipoxygenase and hydroperoxide lyase. Appl. Microbiol. Biotechnol. 2012, 93, 159-168. 
25. Zhang, B.; Yin, X.R.; Li, X.; Yang, S.L.; Ferguson, I.B.; Chen, K.S. Lipoxygenase gene expression in ripening kiwifruit in relation to ethylene and aroma production. J. Agric. Food Chem. 2009, 57, 2875-2881.

26. Qin, G.H.; Tao, S.T.; Cao, Y.F.; Wu, J.; Zhang, H.P.; Huang, W.J.; Zhang, S.L. Evaluation of the volatile profile of 33 Pyrus ussuriensis cultivars by HS-SPME with GC-MS. Food Chem. 2012, 34 , $2367-2382$.

Sample Availability: Samples of the fruits are available from the authors.

(C) 2014 by the authors; licensee MDPI, Basel, Switzerland. This article is an open access article distributed under the terms and conditions of the Creative Commons Attribution license (http://creativecommons.org/licenses/by/4.0/). 